Crônicas de direito internacional ............................................................. Julia Motte-Baumvol e Alice Rocha da Silva

BRAZILIAN TRADE POLICY IN HISTORICAL PERSPECTIVE: CONSTANT FEATURES, ERRATIC BEHAVIOR..11 Paulo Roberto de Almeida

Aspectos GEopolíticos do GAT'T E DA OMC .........................................................28 José Fontoura Costa

A REgulaÇÃo INTERNACIONAL dos SUbSídios AGRÍCOLAS: A CONTEMPORANEIDADE DO PARADIGMA REALISTA PARA A COMPREENSÃO DO SISTEMA DE COMÉRCIO AGRÍCOLA INTERNACIONAL VIGENTE

Natália Fernanda Gomes

ACORDO TRIPS: ONE-SIZE-FITS-ALL?

Tatianna Mello Pereira da Silva

É INTERESSANTE PARA O BRASIL ADERIR AO ACORDO SOBRE COMPRAS GOVERNAMENTAIS DA OMC?

Clarissa Chagas Sanches Monassa e Aubrey de Oliveira Leonelli

A Defesa COMERCIAL E A RESTRIÇÃo dA LIBERALIZAÇÃo E DA INTEGRAÇÃo COMERCIAL PELO AUMENTO DA ALÍQUOTA DE IPI DE VEÍCULOS IMPORTADOS NO BRASIL...................................86

Ricardo Serrano Osorio e Clayton Couto

A COOPERAÇÃo INTERNACIONAL NA DEFESA DA CONCORRÊNCIA

Vinicius Marques de Carvalho e Paulo Burnier da Silveira

Os ACORDOS DE COMÉRCIO PARA ALÉM DAS PREFERÊNCIAS: UMA ANÁLISE DA REGULAMENTAÇÃO SOBRE OS "NOVOS TEMAS" 105

Michelle Ratton Sanchez Badin e Lucas da Silva Tasquetto

INTEGRAÇÃO ECONÔMICA NO MERCOSUL: OPINIÕES CONSULTIVAS E A DEMOCRATIZAÇÃO NO ACESSO AO TRIBUNAL PERMANTE DE REVISÃO 128 Eduardo Biachi Gomes

"Fundos abutres" vs. Estados NaCionais: SObERANiA E ATUAÇÃo do Tribunal INTERNACIONAL do Direito do Mar a partir do Caso da Fragata libertad.. 138 Alexandre Pereira da Silva e Mariana Yante Barrêto Pereira

INVESTIMENTO ESTRANGEIRO: O PADRÃO DE TRATAMENTO JUSTO E EQUITATIVO E O PAPEL DA BOA-FÉ 
Fernando Santos Arenhart

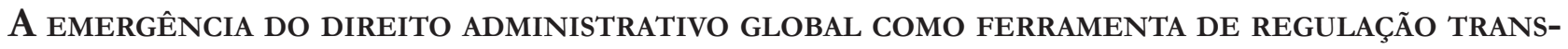
NACIONAL DO INVESTIMENTO ESTRANGEIRO DIRETO .................................................. 171

Andréa Rocha Postiga

Is INVESTMENT ARBITRATION AN APPROPRIATE VENUE FOR ENVIRONMENTAL ISSUES? A LATIN AMERICAN PERSPECTIVE.

Nitish Monebhurrun

A jurisprudência do Superior Tribunal de Justiça e a construção de um Conceito de

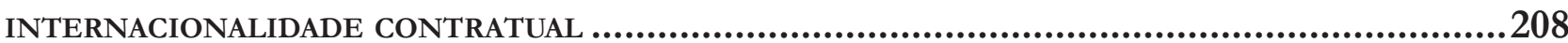

Frederico E. Z. Glitz

IMPACTO E INFLUÊNCIA DOS TRATADOS E CONVENÇÕES INTERNACIONAIS SOBRE A LEI BRASILEIRA DE ARBITRAGEM

Jamile Bergamaschine Mata Diz e Clarissa Correa Neto Ribeiro

A JURISPRUdÊNCIA NORTEAMERICANA E EUROPEIA SOBRE OS ACORDOS HORIZONTAIS E VERTICAIS: SUBSTRATO PARA ANÁLISE DA MATÉRIA NO BRASIL.

Daniel Amin Ferraz 


\section{A regulação internacional dos subsídios agrícolas: a contemporaneidade do paradigma realista para a compreensão do sistema de comércio agrícola internacional vigente}

\section{The international regulation of agricultural subsidies: the contemporaneity of the realistic paradigm for the understanding of the current international agricultural tradesystem.*}

Natália Fernanda Gomes

Especialista em Direito Internacional pela Faculdade de Direito da Universidade Federal de Goiás e mestranda em Direito Agrário pela Faculdade de Direito da Universidade Federal de Goiás. Email: nataliagomesadv@gmail.com

* Recebido em 17/10/202

Aprovado em 03/02/2013

\section{Resumo}

Considerando os efeitos perversos que a concessão indiscriminada de subsídios pelos países centrais pode causar aos países em desenvolvimento e, ainda, que a regulação internacional existente sobre o tema não foi capaz de solucionar esse problema, o presente artigo científico busca analisar, a partir dos preceitos estabelecidos pelo paradigma realista das relações internacionais, as forças de poder atuantes e os interesses dos Estados subjacentes às negociações internacionais estabelecidas para regular o setor agrícola. Por meio de levantamento bibliográfico e a partir da análise crítica e histórica da legislação internacional existente sobre a concessão de subsídios agrícolas, o presente estudo demonstra o predomínio das nações centrais, mormente dos Estados Unidos da América e da União Europeia, nos deslindes do regramento internacional vigente, o qual terminou por consolidar os interesses internos desses países, mesmo quando em detrimento de outras nações. Destinado aos estudiosos de relações internacionais e de direito internacional, o presente trabalho é original e se demonstra salutar para a compreensão não apenas das normas existentes para regular a concessão de subsídios agrícolas pelos países, mas também das forças de poder atuantes na formação da regulação vigente, de modo a demonstrar a contemporaneidade dos preceitos estabelecidos pelo paradigma realista das relações internacionais para a compreensão do sistema internacional como um todo.

Palavras-chave: Subsídios agrícolas. Paradigma realista das relações internacionais. Organização Mundial do Comércio. Acordo sobre agricultura. Acordo sobre medidas compensatórias. Desenvolvimento.

\section{Abstract}

Considering the perverse effects that the indiscriminate granting of subsidies by the central countries may cause to developing ones, and that the existing international regulation on the subject has not been able to solve this problem, this paper seeks to analyze, from the precepts established by the realistic paradigm of international relations, the forces and the interests of the States 
underlied in the international negotiations established to regulate the agricultural sector. Through bibliographical survey and from a historical and critical analysis of the existing international legislation on agricultural subsidies, the present study demonstrates the predominance of the central nations, especially the United States of America and the European Union, in the established international laws, which ended up consolidating the internal interests of these countries, even in detriment of other nations. Intended for scholars of international relations and international law, the present work is original and able to help the understanding not only of the existing regulations about the granting of agricultural subsidies by countries, but also of the powers active in the formation of the current regulation, being able to demonstrate the contemporaneity of the precepts established by the realistic paradigm of international relations for the understanding of the current international system as a whole.

Keywords: Agricultural subsidies. Realistic paradigm of the international relations. World trade organisation. Agreement on agriculture. Agreement on subsidies and countervailing measures. Development.

\section{INTRODUÇão}

A concessão de subsídios agrícolas, em situações específicas e em níveis razoáveis, pode ser justificada sob a perspectiva do aumento do bem-estar social, podendo ser legitimamente utilizada pelos Estados como forma de investimento em infraestrutura, tecnologia e transporte, de promoção do desenvolvimento rural e regional, de redistribuição de renda e, ainda, de proteção do meio ambiente. Por isso, todos os países, em maiores ou menores graus, subsidiam suas produções agrícolas. ${ }^{2}$

Contudo, no atual contexto de integração dos mercados propiciado pela globalização econômica mundial, os mecanismos internos governamentais de política

\footnotetext{
2 Nesse sentido, estudos desenvolvidos pela Organização para a Cooperação e o Desenvolvimento Econômico (OECD) apontam que, no período entre 2009 e 2011, o país com o menor nível de subsídio ao setor agrícola foi a Nova Zelândia $(1 \%$ da renda agrícola), seguido da Austrália (3\%) e do Chile (4\%). Nos EUA, o percentual de subsídio aplicado sobe para $9 \%$ da renda agrícola, 16\% no Canadá e 20\% nos países que compõem a União Europeia. ORGANISATION FOR ECONOMIC CO-OPERATION AND DEVELOPMENT. Agricultural policies in OECD countries and emerging economies. OECD Publishing, 2011.
}

agrícola podem produzir efeitos no comércio internacional, atingindo terceiros países.

Assim, dependendo da quantidade de recursos alocados, do tamanho da economia que os concede e do setor beneficiado, os subsídios distorcem os preços, alteram a quantidade de produtos produzidos e consumidos, realocam recursos e privilegiam determinados grupos em detrimento de outros, causando distorções comerciais que extrapolam o âmbito interno e atingem as relações estabelecidas multilateralmente.

Isso decorre do fato de que, tais medidas, mesmo quando direcionadas à produção interna, dependendo de seu vulto, propiciam a formação de excedentes exportáveis a preços abaixo do custo de produção que, uma vez no mercado internacional, diminuem a competitividade dos produtores não subsidiados.

Como os países em vias de desenvolvimento geralmente subsidiam seu setor agrícola em níveis muito inferiores aos realizados pelos países desenvolvidos, essas políticas podem ter, em longo prazo, efeitos perversos à sua soberania alimentar e ao seu crescimento econômico e agroindustrial, constituindo obstáculos ao desenvolvimento, precisamente no setor em que possuem vantagens comparativas de produção.

Nesse sentido, estudos da Organização das Nações Unidas para Agricultura e Alimentação (FAO), desenvolvidos junto à Conferência das Nações Unidas sobre Comércio e Desenvolvimento (UNCTAD), apontam que os subsídios fornecidos pelos países desenvolvidos estariam associados ao aumento das importações de alimentos pelos países em desenvolvimento e à diminuição da produção agrícola interna. ${ }^{3}$

Em função disso, países tradicionalmente exportadores de alimento, como a República do Gana, teriam se tornado, nos últimos 20 anos, dependentes exclusivamente da importação de alimentos subsidiados. ${ }^{4}$

Nesse mesmo sentido, o Banco Mundial estima que os subsídios fornecidos pelos países desenvolvidos ao setor agrícola custam aos produtores dos países em vias de desenvolvimento mais de $\mathrm{U} \$ 30$ bilhões por ano e

3 UNITED NATIONS CONFERENCE ON TRADE AND DEVELOPMENT. Addressing the global food crises: key trade, investment and commodity policies in ensuring sustainable food security and alleviating poverty. New York and Genebra, 2008.

4 UNITED NATIONS CONFERENCE ON TRADE AND DEVELOPMENT. The 2008 food price crises: rethinking food security policies. G24 Discussion Paper Series, 2009. 
que, se todos esses subsídios fossem extirpados, o setor teria lucro anual adicional de cerca de $\mathrm{U} \$ 250$ bilhões, dos quais quase $\mathrm{U} \$ 150$ bilhões seriam provenientes de países em desenvolvimento. ${ }^{5}$

Trata-se de um tema controverso que envolve contraposições internas entre os interesses de pequenos e grandes agricultores ao mesmo tempo em que envolve interesses distintos entre países centrais e periféricos.

Por isso, a regulação internacional do setor agrícola representa um desafio às negociações multilaterais, estando a limitação à concessão de subsídios agrícolas pelos países no núcleo dos principais impasses da atualidade acerca da regulação do comércio agrícola internacional.

De fato, trata-se de um dos temas centrais das atuais discussões travadas no âmbito da Rodada Doha da Organização Mundial do Comércio (OMC) e sobre o qual o consenso entre os países, a fim de alcançar maior liberalização do setor agrícola, torna-se cada vez mais difícil de ser alcançado.

O embate se trava essencialmente entre os países desenvolvidos, em especial os Estados Unidos da América (EUA) e os países da União Europeia (UE) cujas tradicionais políticas agrícolas intervencionistas se consubstanciam na concessão indiscriminada de subsídios ao setor agrícola, e os países em desenvolvimento, especialmente aqueles que compõem os BRICs ${ }^{6}$ (Brasil, Rússia, Índia, China e África do Sul), os quais consideram os subsídios fornecidos pelos países centrais desleais por distorcerem os preços e as condições de concorrência no comércio agrícola internacional e, por isso, pleiteiam a extirpação deles do sistema.

FOOD AND AGRICULTURE ORGANIZATION OF THE UNITED NATIONS. Subsidies, food imports and tariffs: key issues for developing countries. 2003. Disponível em: <http://www.fao.org/ english/newsroom/focus/2003/wto2.htm>. Acesso em: 16 out. 2012.

6 A sigla, que foi criada pelo banco Goldman Sachs em 2001 como "Bric" para se referir ao bloco de países com economias emergentes - formado por Brasil, Rússia, Índia e China - capaz de influenciar decisivamente nas esferas política e econômica mundiais, passou a incluir a África do Sul em 2011, tornando-se "Brics", também conhecida como "os cinco grandes". Depois de cunhada, a sigla passou a ser amplamente utilizada como um símbolo de mudança no poder econômico global, em contraposição ao grupo dos países desenvolvidos e, embora ainda não se trate de um bloco econômico ou uma associação de comércio formal, os países que o compõem buscam alianças e estratégias conjuntas para tentar converter seu crescimento econômico em maior influência geopolítica.
Em que pese, a partir da década de 1990, ter-se buscado, em nível internacional, a regulação do setor agrícola a fim de minar as distorções existentes no mercado e suas consequências, esse processo regulatório não foi capaz de estabelecer um sistema de comércio agrícola justo e orientado pelo mercado, que proporcione progressivas e substanciais reduções nas formas de apoio, para corrigir e prevenir distorções no mercado agrícola global.

Pelo contrário, os acordos, iniciados no âmbito da OMC pelo Acordo sobre Agricultura (ASA) ${ }^{8}$ e pelo Acordo sobre Subsídios e Medidas Compensatórias (ASMC), ${ }^{9}$ são apontados por estudiosos ${ }^{10}$ como mecanismos que, embora tenham representado um avanço na regulamentação internacional do setor, possuem lacunas e permitem exceções que acomodam as práticas distorcivas presentes nas políticas agrícolas dos EUA e da UE ou dificultam a apuração e o controle dessas práticas.

A acomodação das práticas distorcivas das nações centrais por esses acordos, principalmente das já praticadas pelos EUA e UE, foi fruto do predomínio desses países na condução e no progresso das negociações travadas durante a Rodada Uruguai.

Vislumbra-se, então, a ocorrência de uma evidente desconexão entre a retórica liberal desses países e suas ações, especialmente no que tange ao setor agrícola, no qual o nível de apoio oferecido se mantém elevado apesar dos compromissos firmados.

Nesse sentido, por exemplo, no que tange aos EUA, observa-se que, após a ratificação do ASMC e do ASA, o montante do apoio interno concedido ao setor agrícola quase triplicou de 1995 a 2001, passando de um valor aproximado de US $\$ 7,7$ bilhões, em 1995, para pouco mais de US $\$ 21$ bilhões, em 2001. ${ }^{11}$ Esse montante, ape-

7 Objetivos lançados no ASA, presentes nos Recitais dois e três do acordo. WORLD TRADE ORGANIZATION. Agreement on agriculture. 1995. Disponível em: <http://www.wto.org/english/docs_e/ legal_e/14-ag.pdf>. Acesso em: 19 jun. 2012.

8 WORLD TRADE ORGANIZATION. Agreement on agriculture. 1995. Disponível em: <http://www.wto.org/english/docs_e/ legal_e/14-ag.pdf>. Acesso em: 19 jun. 2012.

9 WORLD TRADE ORGANIZATION. Agreement on subsidies and countervailing measures. 1995. Disponível em: <http://www.wto.org/ english/docs_e/legal_e/24-scm.pdf>. Acesso em: 18 jun. 2012.

10 Dentre os quais: DANTAS, Adriana. Subsídios agrícolas: regulação internacional. São Paulo: Saraiva, 2009.

11 FIGUEIREDO, Adelson Martins et al. Impacto dos subsídios agrícolas dos Estados Unidos na expansão do agronegócio brasileiro. Estudos Econômicos, São Paulo, v. 40, 2010. 
sar de ter sofrido modestas variações em períodos específicos, continua a aumentar.

De fato, a magnitude dos subsídios fornecidos pelos EUA é tão expressiva que o Congresso norte-americano já teria, inclusive, reconhecido que o custo total de produção de determinadas commodities poderia ser coberto apenas com os subsídios fornecidos pelo governo americano. $^{12}$

Há, portanto, um cenário no qual os países centrais se portam de modo ambivalente, defendendo a liberalização comercial apenas nos setores e nas medidas que lhes convém, e no qual os interesses de alguns países são defendidos internacionalmente em detrimento dos demais, por mais graves que possam ser as consequências porventura advindas dessas ações.

Para auxiliar a compreensão desse cenário, recorreremos, neste trabalho, aos preceitos estabelecidos pelo paradigma realista e por suas derivações para fundamentar a compreensão da realidade internacional.

Tais preceitos, embora inicialmente elaborados após a Segunda Guerra Mundial para a compreensão do sistema internacional que se formava, estabelecem princípios e elementos que ainda se demonstram presentes nas relações estabelecidas atualmente entre os países no âmbito global, fornecendo elementos que nos auxiliarão na compreensão do sistema internacional vigente e das forças de poder nele atuantes.

O paradigma realista não compreende, contudo, uma única versão. Abrange desde seus teóricos tradicionais, como Edward Carr em sua obra "Vinte Anos de Crise" e Hans Morgenthau em seu clássico "A Política entre as Nações", todos fortemente marcados pela perspectiva de divisão bipolar mundial vigente durante o período de Guerra Fria, até as versões mais modernas que enquadram na análise as novas variáveis econômicas que surgiram no cenário internacional após a queda do muro de Berlim, como as defendidas pelos autores Joseph Nye Júnior e Robert Keohane.

Todas essas perspectivas teóricas, entretanto, de forma mais ou menos acentuada, apresentam características gerais e premissas comuns acerca do funcionamento do sistema internacional que podem ser destacadas para caracterizar o paradigma realista como um todo.

$1^{2}$ DANTAS, Adriana. Subsidios agrícolas: regulação internacional. São Paulo: Saraiva, 2009. p. 168.
Tais elementos fundamentais e gerais da teoria realista serão, em um primeiro momento, objeto de análise do presente trabalho.

Analisadas as características e a forma como o paradigma realista retrata o sistema internacional, buscar-se-á analisar as forças de poder atuantes e os interesses subjacentes à regulação internacional existente sobre subsídios agrícolas.

Posteriormente, serão correlacionados os principais pontos do paradigma realista com as negociações internacionais firmadas no âmbito multilateral para formação da regulação existente acerca dos subsídios agrícolas.

Verificar-se-á, então, se o paradigma realista das relações internacionais ainda se demonstra adequado para a compreensão das relações estabelecidas pelos Estados na elaboração das normas internacionais vigentes.

\section{Desenvolvimento}

\subsection{Noções elementares do paradigma realista das relações internacionais}

A teoria realista das relações internacionais surgiu no século XX, visando criar um arcabouço teórico capaz de compreender a realidade internacional que surgia no contexto imediatamente posterior à Segunda Guerra Mundial, na qual a formação de dois blocos econômicos antagônicos e rivais e a constante ameaça de guerra atômica colocavam em xeque as possibilidades de se alcançar a paz mundial, nos termos até então defendidos pelos teóricos idealistas. ${ }^{13}$

Fortemente inspirado nos pensamentos do filósofo inglês Thomas Hobbes, ${ }^{14}$ o realismo construiu seus preceitos a partir da noção hobbesiana de que os ho-

\footnotetext{
13 Até então considerados correntes dominantes na compreensão das relações internacionais, os teóricos idealistas, inspirados em Kant, acreditavam na perfectibilidade humana e defendiam a possibilidade de haver paz entre as nações por meio da cooperação entre Estados e do aperfeiçoamento das instituições internacionais. GONÇALVES, Williams. Relações internacionais. 2. ed. Rio de Janeiro: Jorge Zahar, 2004. p. 17.

14 Motivo pelo qual é também conhecido pela denominação de "Paradigma Hobbesiano das Relações Internacionais". GONÇALVES, Williams. Relações internacionais. 2. ed. Rio de Janeiro: Jorge Zahar, 2004.p. 31.
} 
mens, no estado de natureza, qual seja, em um ambiente no qual inexiste autoridade superior capaz de impor e implementar regras de convivência, vivem em uma situação de conflito permanente, na qual todos disputam pelo acúmulo de poder e cada um se torna responsável pela própria preservação, em um jogo de "soma zero", no qual os recursos disponíveis são escassos e não compartilháveis, o que ocasiona permanente disputa. ${ }^{15} \mathrm{Tal}$ estado permanente de guerra "de todos contra todos" só poderia ser revertido, possibilitando a convivência humana, caso os indivíduos se submetessem, por um pacto social, a um governo forte e capaz de controlar as tendências destrutivas humanas. ${ }^{16}$

Esse cenário hobbesiano foi transposto pelos autores realistas para o contexto global, estabelecendo paralelos entre o estado de natureza e o sistema internacional vigente, uma vez que nele não existe um governo central ou uma autoridade suprema acima dos próprios Estados.

Desse modo, o sistema internacional é caracterizado como anárquico, contendo múltiplos Estados soberanos que buscam satisfazer seus próprios interesses, agindo livremente para fazer o que desejam.

Nesse ambiente de anarquia, os Estados se portam politicamente como os indivíduos retratados por Hobbes, ou seja, egoisticamente e movidos predominantemente pela busca da satisfação de seus próprios interesses, e não por noções morais, éticas, religiosas ou ditas universais. ${ }^{17}$

Assim, o Estado é apresentado como um agente internacional unitário e racional, que representa seus nacionais, buscando maximizar seus ganhos e minimizar suas perdas, na satisfação de seus próprios interesses, no cenário internacional. ${ }^{18}$

\footnotetext{
15 LACERDA, Gustavo Biscaia de. Algumas teorias das relações internacionais: realismo, idealismo e grocianismo. Revista Intersaberes, v.1, n.1, 2006, p. 59. Disponível em: < http://www.grupouninter. com.br/intersaberes/index.php/revista/article/view/87>. Acesso em: 07 ago. 2012.

16 SILVA, Marcos Valle Machado da. O Leviatã de Thomas Hobbes como base para o entendimento do paradigma realista das relações internacionais. Revista Iluminart, Sertãozinho, v. 1, n.6, 1984, p. 108.

17 Reinhold Niebuhr (1892 - 1971), em sua obra "Moral Man and Immoral Society", considera hipócritas e pouco eficientes as políticas externas executadas a partir de princípios morais universais. No mesmo sentido: MORGENTHAU, Hans J. A politica entre as nacões. Trad. Oswaldo Biato. Brasília: Universidade de Brasília, 2003.

18 ROSAS, Geraldine M. M. B. Hobbes versus Locke: a contribuição do estado de natureza para as perspectivas realista e pluralista das relações internacionais. Revista e-Civitas, v. 2, n. 1, 2009.
}

A liberdade geral que os Estados possuem de agir na busca de seus interesses, mesmo quando em detrimento dos demais Estados, cria constante desconfiança entre as nações e um ambiente internacional hostil, no qual há um estado permanente de conflito ou disputa por poder que faz com que os Estados busquem meios para sua permanência no sistema ou, em alusão a Hobbes, meios para "garantir a sua própria sobrevivência". ${ }^{19}$

A liberdade de agir é limitada apenas pela capacidade dos outros Estados, ou seja, pelas relações de poder estabelecidas frente aos demais. Essas relações de poder garantem a dominação do Estado mais forte sobre o mais fraco e justificam a formação de alianças entre Estados para garantir hegemonia, poder ou a própria segurança.

O direito e as organizações internacionais, criadas e mantidas pelos Estados, para os realistas, demonstram-se pouco eficazes em reverter essa dinâmica de poder e dominação, pois suas ações refletem as relações de poder já estabelecidas e os interesses dos Estados dominantes.

Vale frisar que, embora para a teoria realista tradicional de Carr e Morgenthau a noção de poder dos Estados se baseasse, mormente, à sua capacidade militar-estratégica e bélica, essa noção foi ampliada, pelos neorrealistas, para incluir as variáveis econômicas, que também permitem relações de poder e dominação.

Nesse sentido, autores como Joseph Nye Jr. e Keohane atualizaram a teoria realista retratando o aspecto econômico como uma verdadeira expressão de poder, por ser um recurso político eficaz, mais até mesmo do que a capacidade militar, para garantir a dominação dos Estados sobre os demais e a própria permanência hegemônica deles no sistema.

Assim, pode-se compreender que as relações de poder, travadas no âmbito militar ou econômico, em um cenário no qual há um natural antagonismo entre os Estados, criam uma ordem internacional momentânea e precária, baseada em um cálculo de vantagens e interesses que pode ser quebrado a qualquer momento. ${ }^{20}$

Disponível em: <http://revistas2.unibh.br/index.php/dcjpg/article/view/25>. Acesso em: 7 ago. 2012.

19 ROSAS, Geraldine M. M. B. Hobbes versus Locke: a contribuição do estado de natureza para as perspectivas realista e pluralista das relações internacionais. Revista e-Civitas, v. 2, n. 1, 2009. Disponível em: <http://revistas2.unibh.br/index.php/dcjpg/article/view/25>. Acesso em: 7 ago. 2012. p. 08.

20 BARNABÉ, Gabriel Ribeiro. As relações internacionais no pensamento de Thomas Hobbes. Revista Philósophos, Goiânia, v. 14, n. 
Esse ambiente instável culmina em problemas de governabilidade que são contornados, segundo os realistas, de forma sintética, por três princípios que regem o sistema internacional, quais sejam: a oligarquia, a hierarquia e o equilíbrio entre poderes. ${ }^{21}$

A oligarquia se refere à multiplicidade de atores existentes no cenário internacional, cada qual com poderes e capacidades variadas, dos quais poucos, efetivamente, possuem poder de decisão política. Assim, apenas poucos Estados são capazes de decidir como todo o sistema internacional funcionará.

Há, então, uma hierarquia na relação entre as nações, na qual, quanto mais poder possuir um país, maior seu potencial de decisão autônoma e de controle e comando sobre os demais.

Originam, daí, vários níveis de comando e de poder no sistema internacional, em um sistema complexo piramidal, em que os Estados mais poderosos podem decidir de forma autônoma, conforme seus interesses internos, e impor suas decisões às nações mais fracas.

Contudo, entre países com o mesmo nível hierárquico existe certo equilíbrio de poder, estabelecido por meio de alianças, de modo que todas as potências mantenham alguma paridade de capacidade de decisão autônoma, que neutralizariam entre si seu potencial crescente de dominação sobre as demais nações mais fracas.

A dinâmica de poder do sistema, advinda desses três princípios básicos, garantiria governabilidade ao sistema internacional, estando o direito ou as organizações internacionais, inclusive, submetidos a essa dinâmica, razão pela qual, para os realistas, esses institutos têm pouca eficácia prática para determinação de mudanças no ambiente internacional.

Nesse sentido, as organizações e as regulações internacionais existentes seriam criadas para garantir as relações de poder já estabelecidas, submeter os países mais frágeis aos interesses das nações mais poderosas e legitimar ações que privilegiam o grupo mais forte em detrimento dos demais.

1, 2009. Disponível em: <https://www.revistas.ufg.br/index.php/ philosophos/article/view/10034\#.UBkzVlLgzso>. Acesso em: 07 ago. 2012.

21 LACERDA, Gustavo Biscaia de. Algumas teorias das relações internacionais: realismo, idealismo e grocianismo. Revista Intersaberes, v.1, n.1, 2006. Disponível em: <http://www.grupouninter.com.br/ intersaberes/index.php/revista/article/view/87>. Acesso em: 07 ago. 2012. p. 61

\subsection{As forças de poder e os interesses subjacen- tes à regulação multilateral existente acerca dos subsídios agrícolas}

Ao término da Segunda Guerra Mundial, as principais nações mundiais decidiram impulsionar e regular suas relações econômicas internacionais com o objetivo de propiciar maior interação entre os povos e diminuir os problemas econômicos que poderiam influir nessas relações, garantindo assim alguma perspectiva de paz entre as nações.

Nesse contexto, foi criado em 1947, durante as negociações tarifárias da Rodada de Genebra, um conjunto de normas e concessões tarifárias que passou a ser denominado Acordo Geral sobre Tarifas e Comércio (GATT).

Embora tenham sido criados, originalmente, para constituir um foro de negociações e de conciliação de práticas comerciais internacionais, os termos de aprovação do GATT sofreram forte influência dos EUA, cujo apoio era fundamental, no momento histórico do pós-guerra, para a efetividade e a própria existência de qualquer acordo comercial.

Nesse contexto, os EUA determinaram a regulação da ordem comercial mundial que se consolidava '[...] apenas ao que lhes afigurava como prioritário, ou seja, a conquista de novos mercados para garantir a vazão da sua produção, superaquecida pelo esforço de guerra, e evitar uma nova fase recessiva". ${ }^{22}$

A liberalização comercial prevista nesse acordo não foi estendida, contudo, ao setor agrícola. De fato, o setor foi excepcionado de todas as rodadas de negociações que compuseram o GAT'T, inclusive do Código de Subsídios firmado na Rodada Tóquio especificamente para regular a concessão de subsídios pelos Estados.

Em que pese a busca dos países periféricos por negociações que estendessem a regulação comercial ao setor agrícola, inclusive no que tange à concessão de subsídios, os primeiros passos estabelecidos internacionalmente, nesse sentido, ocorreram apenas em 1994, na Rodada Uruguai, com a instituição da OMC e a concomitante assinatura do ASMC e do ASA.

\footnotetext{
${ }^{22}$ MAGALHÃES, Luiz Roberto Paranhos de. Subsídios na disciplina da Organização Mundial do Comércio - OMC: a necessidade de maior liberdade para a ação governamental nos países em desenvolvimento. Rio de Janeiro: Forense, 2007. p. 76 .
} 
O ASMC e o ASA, no entanto, apesar de representarem um avanço na regulamentação internacional do setor, abrigam lacunas e permitem exceções que acomodam práticas distorcivas praticadas pelas nações centrais ou dificultam a apuração e controle dessas práticas.

A acomodação de práticas distorcivas, principalmente das já praticadas pelos EUA e pela UE, foi fruto do predomínio desses países na condução e no progresso das negociações travadas, na qual os seus aceites foram claramente condicionados à acomodação de seus interesses internos aos compromissos multilaterais que surgiam.

Nesse sentido, Adriana Dantas destaca que: "Verificou-se, na prática, que os pontos mais sensíveis foram solucionados de forma bilateral (entre EUA e UE) e, depois, estendidos às demais partes envolvidas na negociação, os futuros membros da OMC". 23

A evidente desconexão entre a retórica liberal desses países, as suas ações e os seus interesses em influenciar os deslindes do regramento internacional, no que tange ao setor agrícola, decorrem do fato de que, apesar de os países em desenvolvimento possuírem maior dependência econômica com relação às atividades agrícolas, o setor é efetivamente dominado no mercado internacional pelas nações desenvolvidas, sendo a UE e os EUA não apenas os principais exportadores mundiais no setor, mas também os maiores subsidiadores mundiais de suas produções. ${ }^{24}$

Consistindo em um primeiro esforço de regulamentação internacional do setor agrícola, o ASMC e o ASA não baniram a concessão de subsídios pelos Estados, reconhecendo a existência de medidas de apoio oferecidas pelos governos que devem ser toleradas, por promoverem o aumento do bem-estar social ou garantirem certo nível de segurança às políticas comerciais das nações.

Contudo, nem todas as medidas excepcionadas e lacunas existentes nesses acordos podem ser justificadas sob esses parâmetros, como será demonstrado a seguir. Vislumbra-se, ao contrário, que muitas das exceções foram estabelecidas para acomodar práticas que beneficiam os países centrais, direta ou indiretamente.

\footnotetext{
23 DANTAS, Adriana. Subsídios agrícolas: regulação internacional. São Paulo: Saraiva, 2009. p.65.

${ }^{24}$ ORGANISATION FOR ECONOMIC CO-OPERATION AND DEVELOPMENT. Agricultural policies in OECD countries and emerging economies. OECD Publiching, 2011.
}

A começar pela definição de subsídios acordada no ASMC, que é a primeira e a única definição multilateral existente sobre o tema, a qual caracteriza os subsídios como uma forma de intervenção governamental na atividade econômica, pela transferência de recursos para produtores ou consumidores específicos, com o objetivo de garantir ou suplementar renda, de reduzir custos e riscos de produção, ou de assegurar pagamentos.

Analisando esse conceito, vislumbra-se que os subsídios, para serem cobertos pela regulação da OMC, devem atender simultaneamente a quatro requisitos, quais sejam: serem medidas que constituam uma contribuição financeira ou que sustentem a renda do produtor ou o preço da produção, serem direta ou indiretamente financiados por um Governo, entidade pública ou, ainda, por uma entidade particular exercendo funções tipicamente governamentais, conferirem um benefício competitivo e, ainda, serem direcionados a um setor, empresa ou atividade específicos.

Essa definição, embora abrangente, revela-se insuficiente para alcançar todos os tipos possíveis de subsídios, deixando em aberto algumas possibilidades de práticas estatais de caráter intervencionista.

Dentre essas possibilidades, destacam-se as políticas omissivas (policy failure), como nos casos de deliberada omissão governamental em impor requisitos ambientais para o desenvolvimento de determinadas atividades econômicas, as quais não são tratadas como subsídios pelo referido acordo, mas podem efetivamente funcionar como tais. ${ }^{25}$

Por outro lado, ao trazer o requisito da especificidade, o ASMC restringe o âmbito de atuação da OMC, pois excepciona de seu regramento os subsídios não específicos, ou seja, aqueles que não são direcionados a uma atividade, empresa ou setor específicos.

Esse requisito prejudica os países mais pobres, cujas baixas poupanças privadas e pequenas economias conduzem o ônus de investir na produção aos próprios Estados e não ao setor privado. Esses governos, diante da insuficiência de recursos para investir em setores amplos, acabam tendo que estabelecer algum critério seletivo e direcionar seus investimentos a setores específicos, atuação que pode, por sua especificidade e caráter go-

\footnotetext{
25 MOLKE, Konrad Von. Negotiating subsidy reduction in the world trade organization. Winnipeg: IISD, 2003. Disponível em: <http://www. iisd.org/pdf/2003/trade_cancun_research_paper.pdf $>$. Acesso em: 18 jun. 2012
} 
vernamental, ser atingida e restringida pelo regramento multilateral. ${ }^{26}$

As críticas, contudo, não repousam apenas nessa restrição do objeto do acordo que, quando não beneficia as nações centrais, também não atua favoravelmente às nações periféricas.

De fato, o disciplinamento da especificidade dos subsídios estabelecida pelo ASMC é bastante similar à definição legal previamente existente sobre o tema na lei sobre medidas compensatórias estadunidenses. ${ }^{27}$ Esse fato reflete a relutância que países centrais apresentam nas negociações internacionais em serem signatários de regramentos que estejam em desacordo com suas leis nacionais.

Tal postura é problemática, pois não apenas pode se traduzir como uma vantagem comparativa a favor dos EUA, como também demonstra a forte influência desse país no desfecho dos acordos firmados e na interpretação dos temas nele regulados. Nos dizeres de Molke:

É geralmente problemático quando a lei internacional segue a lei doméstica muito proximamente, e o GATT/OMC tem sido influenciado com frequência pelas leis e práticas estadunidenses. $\mathrm{O}$ país em questão passa a usufruir de uma vantagem imediata na implementação (da medida regulada). Ele desfruta de vantagens na interpretação em razão de seus especialistas estarem mais familiarizados com o texto. Essa prática também sugere aos decisores políticos do país em questão que todos os outros países devam interpretar o texto da mesma maneira que eles o interpretam em suas relações multilaterais e unilaterais. Ainda que cada país deva adaptar o texto internacional dentro de seu próprio sistema político, legal e administrativo [...], a tendência é que siga a doutrina legal norte-americana existente $[\cdots]^{28}$ (tradução nossa).

${ }^{26}$ MAGALHÃES, Luiz Roberto Paranhos de. Subsídios na disciplina da Organização Mundial do Comércio - OMC: a necessidade de maior liberdade para a ação governamental nos países em desenvolvimento. Rio de Janeiro: Forense, 2007, p. 123.

${ }^{27}$ MOLKE, Konrad Von. Negotiating subsidy reduction in the world trade organization. Winnipeg: IISD, 2003. Disponível em: < http://www. iisd.org/pdf/2003/trade_cancun_research_paper.pdf>. Acesso em: 18 jun. 2012. p. 07.

28 "It is generally problematic when an international text follows domestic Law of a single country too closely, but the GATT/WTO has often been influenced by U.S. Law and practice. The country in question enjoys immediate advantage in implementation. It enjoys a further advantage in interpretation by virtue of the fact that its experts are more familiar with the text. Such a practice also suggests to policy-makers of the country in question that all other countries should read the texts in the same manner as they implement them multi-unilaterally. Yet each country must adapt international legal texts into its own political, legal and administrative systems, with the
A primazia dos interesses dos países centrais também é percebida no regime de controle da concessão de subsídios estabelecido pelo ASMC e pelo ASA, restando consolidada nesses acordos uma clara assimetria entre a regulação aplicável aos produtos agrícolas e aos bens industriais.

Enquanto o ASMC proíbe, em qualquer circunstância para o setor industrial, os subsídios destinados a financiar o desempenho exportador, otimizando-lhe os resultados, ou o produtor, pelo uso preferencial do produto de origem nacional em detrimento do produto estrangeiro, ${ }^{29} \mathrm{vi}-$ sando coibir a concessão pelos Estados de subsídios que interfiram diretamente no desempenho exportador dos países; essa completa restrição não foi estendida ao setor agrícola, no qual todo subsídio, inclusive os direcionados à exportação ou à substituição das importações, é permitido até certo limite, estabelecido no ASA.

Desse modo, são proibidos apenas os subsídios à exportação que não estejam explicitamente consolidados nas listas de compromissos individuais constantes no ASA, sendo autorizada a concessão de todas as medidas consolidadas, nos níveis estabelecidos nas listas de compromissos.

A esse respeito, vale frisar que os EUA apenas tiveram seu programa governamental "Step 2" condenado pelo Órgão de Solução de Controvérsias (OSC) da OMC em 2005, no procedimento que ficou conhecido como "Contencioso do Algodão", pois o programa conferia subsídios à exportação do algodão, produto que não estava inscrito na lista estadunidense de compromissos em termos de subsídios à exportação. ${ }^{30}$

De modo geral, a regulação internacional firmada não foi capaz de reduzir o uso dos subsídios à exportação pelos países, principalmente pelas nações desenvolvidas, que representam cerca de $98 \%$ da utilização desse tipo de medida, ou seja, quase a totalidade da utilizada no cenário global. ${ }^{31}$

result that there will be significant variations from one country to the next. The tendency to follow U.S. legal doctrine reflects both the dominance of U.S. economic concepts in international economic negotiations and the deep reluctance of U.S. policy-makers to accept any international legal text that does not conform to existing U.S. law."Cf. Idem.

29 MAGALHÃES, Luiz Roberto Paranhos de. Subsídios na disciplina da Organização Mundial do Comércio - OMC: a necessidade de maior liberdade para a ação governamental nos países em desenvolvimento. Rio de Janeiro: Forense, 2007. p. 122-123.

30 CEDRO, Rafael Rosa. Desenvolvimento rural e a OMC: a experiência do Brasil. Curitiba: Juruá, 2011. p. 118.

31 CEDRO, Rafael Rosa. Desenvolvimento rural e a OMC: a experiência 
Isso decorre do fato de os níveis de apoio autorizados nas listas individuais de concessão da ASA serem bastante altos. $\mathrm{Na}$ prática, os níveis se demonstram suficientes não apenas para preservar boa parte das políticas agrícolas estruturadas na concessão de subsídios à exportação, mas também para fornecer margem de aplicabilidade substancialmente maior do que a atualmente praticada, especialmente para os países centrais.

Desse modo, apesar da queda de cerca de $60 \%$ na concessão de subsídios à exportação agrícola ocorrida entre 1995 e 2000 na UE, os integrantes das comunidades europeias estariam autorizados pelo ASA a conceder cerca de US\$ 7 bilhões em medidas como essas, valor equivalente ao montante mundial de subvenções concedidas à exportação no ano de 1995. ${ }^{32}$

Isso demonstra que a redução ocorrida pode cessar e ser revertida a qualquer momento, não tendo sido determinada pela regulação internacional existente, mas sim em virtude de prioridades e necessidades estratégicas nacionais momentâneas.

A respeito da assimetria posta entre os subsídios proibidos aos setores industrial e agrícola, leciona Magalhães que:

\begin{abstract}
A não-extensão dos subsídios proibidos ao setor agrícola) representa o caráter sob medida dos acordos da OMC em favor dos interesses hegemônicos, já que o acúmulo de conquistas sócio-trabalhistas, carga tributária e, por vezes, as próprias condições naturais para o cultivo de certas lavouras, encarecem a produção agrícola nos países ricos. ${ }^{33}$
\end{abstract}

Os subsídios não proibidos podem ser questionados junto ao OSC/OMC pelos países membros da OMC mediante a comprovação de que provocam, ou têm o potencial de provocar prejuízos graves.

O procedimento junto ao OSC/OMC, nesse caso, requer a prova da existência do efetivo dano grave ou do risco iminente de seu implemento e do nexo causal entre a medida questionada e o dano apontado.

Trata-se, contudo, de um procedimento moroso, com atividade probatória extenuante, que representa alto custo aos países, em especial aos mais pobres, razão pela qual nem sempre lhes é viável utilizá-lo.

do Brasil. Curitiba: Juruá, 2011. p. 132.

32 CEDRO, Rafael Rosa. Desenvolvimento rural e a OMC: a experiência do Brasil. Curitiba: Juruá, 2011. p. 132.

33 MAGALHÃES, Luiz Roberto Paranhos de. Subsídios na disciplina da Organização Mundial do Comércio - OMC: a necessidade de maior liberdade para a ação governamental nos países em desenvolvimento. Rio de Janeiro: Forense, 2007. p. 126.
Sobre esse aspecto, Magalhães ressalta o fato de os pagamentos dos elevados custos, resultantes dos procedimentos e da defesa dos direitos junto ao OSC/OMC, terem que ser realizados na Suíça, onde se localiza a sede da OMC, em moeda forte (euro), o que representa clara desvantagem aos países mais pobres quando eles precisam se valer do procedimento. ${ }^{34}$

Há, enfim, aqueles subsídios que são protegidos pela regulação internacional, por trazerem benefícios sociais ou garantirem certo nível de segurança política aos países. Trata-se de medidas governamentais que, em princípio, não podem ser questionadas, por não serem consideradas distorcivas ao comércio internacional.

Integram essa categoria os subsídios não específicos e os subsídios específicos que se destinarem à atividade de pesquisa, à redução das desigualdades regionais ou à adaptação de instalações existentes às exigências legais de caráter ambiental.

Foram resguardados também os subsídios considerados importantes para o desenvolvimento social e econômico dos países, em especial dos mais pobres. Nesse sentido, o ASMC oferece regras de tratamento especial e diferenciado para os países de menor desenvolvimento relativo, autorizando-os a desenvolver algumas políticas intervencionistas.

Tais regras, contudo, são tratadas como medidas excepcionais e não se demonstram suficientes para induzir o desenvolvimento dos países que delas socialmente necessitam, pois têm suas possibilidades lícitas de admissão em casos muito restritos.

Assim, há limites percentuais aos subsídios destinados à pesquisa e à adaptação de unidades produtivas às leis de preservação ambiental, e, quanto ao fomento das regiões economicamente carentes, ele só ocorre sem maiores restrições quando for destinado a áreas nitidamente identificadas, se o problema a ser sanado não for considerado temporário, se o desemprego na região for $10 \%$ maior do que no resto do país e a renda per capta for inferior a $85 \%$ da média nacional. ${ }^{35}$

\footnotetext{
34 MAGALHÃES, Luiz Roberto Paranhos de. Subsídios na disciplina da Organização Mundial do Comércio - OMC: a necessidade de maior liberdade para a ação governamental nos países em desenvolvimento. Rio de Janeiro: Forense, 2007. p. 137.

35 MAGALHÃES, Luiz Roberto Paranhos de. Subsídios na disciplina da Organização Mundial do Comércio - OMC: a necessidade de maior liberdade para a ação governamental nos países em desenvolvimento. Rio de Janeiro: Forense, 2007. p. 139.
} 
Esses critérios são bastante questionáveis, pois, em se tratando de países onde o subdesenvolvimento campeia todo o território nacional, torna-se absurdo estabelecer gradações de miséria para que um Estado possa intervir em determinados setores ou regiões.

Vale destacar, ademais, que existem dúvidas quanto ao atual status de vigência dessa proteção oferecida aos países de menor desenvolvimento relativo, pois, nos termos do ASMC, esse disciplinamento seria aplicável por apenas cinco anos, contados a partir de 1995 - período que não foi renovado por qualquer acordo posterior.

O não resguardo dessas medidas é preocupante, pois teria o condão de ampliar ainda mais as assimetrias existentes entre os países centrais e periféricos, não apenas em suas relações comerciais internacionais, mas inclusive em termos de desenvolvimento nacional.

A respeito da categoria dos subsídios ditos não acionáveis, de sua vigência e de sua aceitabilidade, Magalhães alerta que se trataria de:

[...] apenas uma concessão politicamente correta por parte das potências econômicas. Foi criada como uma espécie de válvula de escape temporária de forma a manter as aparências nobres do acordo, cooptando o necessário apoio numérico dos países pobres. $^{36}$

No que tange à regulação dos subsídios concedidos como medidas de política agrícola doméstica, o ASA criou mecanismos de controle por meio do enquadramento dessas medidas em três diferentes grupos, ou "caixas", segundo a linguagem de praxe da OMC.

A primeira categoria, denominada "caixa verde", abarca as medidas que, por não apresentarem impactos sobre o comércio e o volume de produção, ou apresentá-los em mínima intensidade, não são submetidas a qualquer compromisso de redução. A segunda categoria, conhecida como "caixa amarela", abarca as medidas que, por afetarem a produção e o comércio, estão sujeitas a compromissos progressivos de redução. A terceira categoria, conhecida como "caixa azul”, enquadrada as políticas que, embora incidam sobre a produção e o comércio (e, por isso, possam ser categorizadas como de caixa amarela), são direcionadas à limitação de produção daqueles produtores que recebem subsídios.

${ }^{36}$ MAGALHÃES, Luiz Roberto Paranhos de. Subsídios na disciplina da Organização Mundial do Comércio - OMC: a necessidade de maior liberdade para a ação governamental nos países em desenvolvimento. Rio de Janeiro: Forense, 2007. p. 139.
Os termos consolidados nesse sistema de regulação, assim como nos casos já analisados, sofreram clara influência dos interesses dos países centrais.

Inicialmente, apesar do caráter restritivo das políticas enquadradas na "caixa amarela", os compromissos de redução dessa categoria foram contabilizados em Medida Agregada de Apoio (AMS, sigla em inglês), ${ }^{37}$ cujo teto máximo foi calculado, por país, com base no montante médio desse tipo de política aplicado entre os anos de 1986 e 1988. A partir desse ponto de partida, foi estabelecido um corte, a ser aplicado gradualmente, de $20 \%$ para os países desenvolvidos e $13 \%$ para os países em desenvolvimento.

Apesar de o corte aplicado aos países em desenvolvimento ser menor do que o concedido às nações desenvolvidas, isso não representou nem um equacionamento das medidas globalmente concedidas, nem um efetivo benefício em favor das nações que mais necessitam de políticas internas de incentivo para seu desenvolvimento.

Isso se deveu ao fato de o teto da AMS ter sido calculado com base em períodos nos quais os membros desenvolvidos, em especial os EUA e UE, tinham concedido altos níveis de subsídios internamente. Assim, o corte realizado perpetuou um desequilíbrio histórico, pois culminou na autorização de concessão de níveis maiores de subsídios domésticos potencialmente distorcivos aos países membros que historicamente já praticavam montantes mais elevados dessas medidas. ${ }^{38}$

As medidas protegidas na terceira categoria, conhecida como "caixa azul", por outro lado, não foram permitidas para fomentar o desenvolvimento periférico, como aparentemente pode transparecer. A categoria foi, de fato, criada para acomodar o Plano MacSharry de 1992, de reforma da Política Agrícola Comum (PAC) das Comunidades Europeias. ${ }^{39}$

Vislumbra-se aqui, mais uma vez, uma prática recorrente dos países centrais nas negociações multilaterais: apenas avançar nas negociações com base em normas já internalizadas, segundo as prioridades de suas políticas internas. A esse respeito, no que tange a UE, destaca Cedro:

\footnotetext{
37 Referente ao termo "Aggregate Measurement of Support".

38 CEDRO, Rafael Rosa. Desenvolvimento rural e a OMC: a experiência do Brasil. Curitiba: Juruá, 2011. p. 112.

39 CEDRO, Rafael Rosa. Desenvolvimento rural e a OMC: a experiência do Brasil. Curitiba: Juruá, 2011. p. 113.
} 
Uma prática recorrentemente utilizada por esse bloco econômico é apenas avançar nas negociações multilaterais com base nas reformas prévias da sua política que já tenham sido feitas internamente. Assim, por um lado, ele tende a negociar apenas quando o tratado em discussão contemple um grau razoável de margem para acomodar as prioridades de política interna. Por outro lado, ele 'vende' os movimentos que ele próprio já tinha interesse de fazer e que aprovou em reformas de sua política $[\ldots]{ }^{40}$

Pelo exposto, pode-se, portanto, perceber a forte influência das nações centrais, em especial dos EUA e dos países que integram a UE, nos deslindes do ASA e do ASMC e o caráter sob medida desses acordos para atender aos seus interesses internos, sem se preocupar em resguardar os interesses dos países periféricos.

\subsection{A análise da regulação do comércio agrícola internacional sob uma perspectiva realista}

Da análise do ASMC e do ASA, vislumbra-se que, apesar de se tratar de um pleito dos países periféricos, a regulação do comércio agrícola mundial, especialmente no que tange à limitação à concessão de subsídios pelos Estados, foi determinada pelos interesses dos países mais poderosos no sistema internacional, ou, nos dizeres realistas, dos mais capazes.

Desse modo, percebe-se que, embora tenha sido constituída para funcionar como um fórum de negociação e conciliação entre os países, de fato, a OMC promoveu uma hierarquização da participação dos Estados, de modo que os interesses das nações centrais preponderaram sobre os interesses dos demais países.

Essa hierarquização permitiu que as leis e as práticas internas desses países fossem resguardadas pelo sistema da OMC e restassem aplicáveis a todas as demais nações, atendendo aos seus interesses internos, mesmo quando em detrimento dos demais.

Surge, assim, um claro sistema piramidal no qual os Estados mais poderosos podem decidir de forma autônoma, conforme seus interesses internos, e impor suas decisões às nações mais fracas, por mais nefastas que possam ser as consequências dessas ações para tais nações.

Nesse diapasão, apesar de todos os membros da OMC teoricamente terem o mesmo nível de direitos

\footnotetext{
40 CEDRO, Rafael Rosa. Desenvolvimento rural e a OMC: a experiência
} do Brasil. Curitiba: Juruá, 2011.p.113. e de proteção, na prática, há uma oligarquia instituída, na qual poucos, efetivamente, têm poder autônomo de decisão.

$\mathrm{Na}$ prática, para a formação do regramento analisado da OMC, apenas alguns Estados, mormente os EUA e os que compõem a UE, decidiram como todo o sistema internacional comercial deveria funcionar.

Essas nações mais poderosas, no que tange aos pontos mais sensíveis a serem regulados, negociaram a solução de forma bilateral, para impor, então, sua decisão aos demais países. A formação de alianças entre as nações de mesmo nível hierárquico garantiu a perpetuação do equilíbrio de poder então vigente.

Às demais nações, menos capazes, restou acatarem as decisões autônomas dos Estados mais fortes, como meio de se inserir no sistema de comércio internacional e garantir sua permanência nesse sistema, ou seja, sua sobrevivência.

Assim, a regulação do comércio internacional, embora criada para garantir a paz entre as nações, na prática, acabou por funcionar como uma forma de legitimação dos interesses racionais das nações mais poderosas no globo e não como um meio de promoção de princípios morais ou universais.

Por isso, a regulação do ASA não foi capaz de atingir seus objetivos traçados, quais sejam: estabelecer um sistema de comércio agrícola justo e orientado pelo mercado, que proporcione progressivas e substanciais reduções nas formas de apoio, para corrigir e prevenir distorções no mercado agrícola global.

Nesse sistema de poder estabelecido hierarquicamente e diante da impossibilidade de negociação isolada dos países em desenvolvimento com as nações centrais para o estabelecimento de regras mais benéficas, a coalizão terceiro-mundista ocorrida a partir 2003, com a formação do G-20, foi essencial para o estabelecimento de uma nova balança de poder capaz, efetivamente, de conceder aos países periféricos algum poder de negociação. Nesse sentido, pode-se dizer que:

Em certa medida, o G-20 que se forma na reunião de Cancun, no México em 2003, representa um renascimento da coalizão terceiro-mundista agora, porém, em torno dos interesses agrícolas dos países em desenvolvimento e na explicitação da hipocrisia da posição de negociação dos países desenvolvidos. 41

${ }_{41}$ LIMA, Maria Regina Soares de. A política externa brasileira e os 
A formação dessa aliança alterou o espaço de ação e de negociação dos governos periféricos e possibilitou a defesa de seus interesses na Rodada Doha de Negociações, que passou a ter como núcleo central a discussão das adequações que deveriam ser feitas às regras multilaterais aplicáveis ao setor agrícola.

Em que pese essa rodada de negociações não ter apresentado grandes resultados, ela representou uma clara alteração dos eixos de negociação e da balança de poder vigente, com formação de eixos combinados de cooperação horizontal e vertical com capacidade de negociação, ${ }^{42}$ tendo, pela primeira vez, apresentado algum potencial de alteração do sistema multilateral que operasse em favor dos interesses das nações periféricas.

\section{Considerações finais}

A concessão de subsídios agrícolas pode ser legitimamente utilizada pelos Estados como forma de investimento em infraestrutura, tecnologia e transporte, de promoção do desenvolvimento rural e regional, de redistribuição de renda e, ainda, de proteção do meio ambiente.

Essas políticas, contudo, nos níveis praticados pelas nações desenvolvidas, podem causar, em longo prazo, efeitos perversos à soberania alimentar e ao crescimento econômico e agroindustrial dos países em desenvolvimento.

Em que pese o conhecimento dos efeitos perversos que essas medidas podem causar, a regulação internacional existente sobre o tema não foi capaz de estabelecer um sistema de comércio agrícola justo e orientado pelo mercado.

Foi demonstrado no presente trabalho que esse fato decorre do predomínio das nações centrais, mormente dos EUA e da UE, nos deslindes do regramento internacional firmado, no qual restaram consolidados os interesses internos desses países, mesmo quando em detrimento de outras nações.

desafios da cooperação sul-sul. Revista Brasileira de Politica Internacional, v. 48, n. 1, 2002. Disponível em: <http://www.scielo.br/pdf/ rbpi/v48n1/v48n1a02.pdf>. Acesso em: 08 ago. 2012.

${ }^{42}$ PECEQUILO, Cristina Soreanu. A política externa do Brasil no século XXI. Revista Brasileira de Politica Internacional, v. 51, n. 2, 2009. Disponível em: <http://www.scielo.br/pdf/rbpi/v51n2/v51n2a09. pdf $>$. Acesso em: 08 ago. 2012.
Esse predomínio foi fruto do poder hierárquico desses Estados frente aos demais no cenário internacional, o que permitiu que eles monopolizassem e equalizassem entre si o poder de decisão autônoma durante as negociações multilaterais.

Tal balança de poder só passou a ser revertida quando as nações mais fracas se uniram, formando um grupo mais forte e com certa capacidade de negociação frente às potências centrais.

Esse cenário, no qual as normas internacionais não decorrem de noções universais de justiça ou moral, mas sim de forças de poder, remete-nos aos aspectos primordiais do paradigma realista das relações internacionais, o qual, embora elaborado inicialmente no contexto pós-guerra, ainda se demonstra atual para a compreensão do sistema internacional vigente.

\section{REFERÊnCIAS}

ANDERSON, Kym; MARTIN, Will. Agriculture, trade reform, and the Doha Agenda. Washington: World Bank, 2006.

ANDERSON, Kym;. VALENZUELA, Ernesto. The relative importance of agricultural subsidies and market acess. World Bank Policy Research Paper 3900, 2006.

BARNABÉ, Gabriel Ribeiro. As relações internacionais no pensamento de Thomas Hobbes. Revista Philósophos, Goiânia, v. 14, n. 1, 2009. Disponível em: <https:// www.revistas.ufg.br/index.php/philosophos/article/ view/10034\#.UBkzVlLgzso>. Acesso em: 07 ago. 2012.

BEDIN, Gilmar Antônio et. al. Paradigmas das relações internacionais. Ijuí: UNIJUI, 2000.

BRUNO, Flávio Marcelo Rodrigues; Azevedo, André Filipe Zago de; Massuquetti, Angélica. Os subsídios à agricultura no comércio internacional: as políticas da União Europeia e dos Estados Unidos da América. Revista Ciência Rural, Santa Maria, v.42, n.4, 2012.

CARVALHO, Maria Izabel Valladão de. Condicionantes internacionais e domésticos: o Brasil e o G-20 nas negociações da Rodada Doha. DADOS, Revista de Ciências Sociais, Rio de Janeiro, v.52, n.2, 2010.

CEDRO, Rafael Rosa. Desenvolvimento rural e a OMC: a experiência do Brasil. Curitiba: Juruá, 2011. 
D’ÁVILA, ANDRÉ LUIZ BETTEGA. O direito do comércio internacional no setor agrícola: subsídios à exportação. Florianópolis. 2006. Dissertação (Mestrado em Direito)-Universidade Federal de Santa Catarina, Florianópolis, 2006.

DANTAS, Adriana. Subsidios agrícolas: regulação internacional. São Paulo: Saraiva, 2009.

EDWARDS, Chris. Agricultural subsidies. CATO Institite, 2007. Disponível em <http://www.downsizinggovernment.org/agriculture/subsidies $>$. Acesso em: 16 out. 2012.

FIGUEIREDO, Adelson Martins et. al. Impacto dos subsídios agrícolas dos Estados Unidos na expansão do agronegócio brasileiro. Estudos Econômicos, São Paulo, v. 40, 2010.

FOOD AND AGRICULTURE ORGANIZATION OF THE UNITED NATIONS. Subsidies, food imports and tariffs: key issues for developing countries. 2003. Disponível em: < http://www.fao.org/english/newsroom/focus/2003/wto2.htm>. Acesso em: 16 out. 2012.

GONÇALVES, Williams. Relações internacionais. 2. ed. Rio de Janeiro: Jorge Zahar, 2004.

LACERDA, Gustavo Biscaia de. Algumas teorias das relações internacionais: realismo, idealismo e grocianismo. Revista Intersaberes, v.1, n.1, 2006. Disponível em: $<$ http://www.grupouninter.com.br/intersaberes/index.php/revista/article/view/87>. Acesso em: 07 ago. 2012.

LIMA, Maria Regina Soares de. A política externa brasileira e os desafios da cooperação sul-sul. Revista Brasileira de Politica Internacional, v. 48, n.1, 2002. Disponível em: <http://www.scielo.br/pdf/rbpi/v48n1/v48n1a02. pdf $>$. Acesso em: 08 ago. 2012.

MAGALHÃES, Luiz Roberto Paranhos de. Subsidios na disciplina da Organização Mundial do Comércio - OMC: a necessidade de maior liberdade para a ação governamental nos países em desenvolvimento. Rio de Janeiro: Forense, 2007.

MOLKE, Konrad Von. Negotiating subsidy reduction in the world trade organization. Winnipeg: IISD, 2003. Disponível em: <http://www.iisd.org/pdf/2003/trade_ cancun_research_paper.pdf $>$. Acesso em: 18 jun. 2012.
MORGENTHAU, Hans J. A política entre as nações. Trad. Oswaldo Biato. Brasília: Universidade de Brasília, 2003.

NAKADA, Minoru. OMC e o regionalismo: análise do art. XXIV e dispositivos afins do acordo de Marraqueche. São Paulo: Aduaneiras, 2002.

ORGANISATION FOR ECONOMIC CO-OPERATION AND DEVELOPMENT. Agricultural policies in OECD countries and emerging economies. OECD Publiching, 2011.

PECEQUILO, Cristina Soreanu. A política externa do Brasil no século XXI. Revista Brasileira de Politica Internacional, v. 51, n. 2, 2009. Disponível em: < http://www. scielo.br/pdf/rbpi/v51n2/v51n2a09.pdf >. Acesso em: 08 ago. 2012.

ROSAS, Geraldine M. M. B. Hobbes versus Locke: a contribuição do estado de natureza para as perspectivas realista e pluralista das relações internacionais. Revista e-Civitas, v. 2, n. 1, 2009. Disponível em: <http:// revistas2.unibh.br/index.php/dcjpg/article/view/25>. Acesso em: 7 ago. 2012.

SILVA, Marcos Valle Machado da. O Leviatã de Thomas Hobbes como base para o entendimento do paradigma realista das relações internacionais. Revista Iluminart, Sertãozinho, v. 1, n.6, 1984.

UNITED NATIONS CONFERENCE ON TRADE AND DEVELOPMENT. Adressing the global food crises: key trade, investment and commodity policies in ensuring sustainable food security and alleviating poverty. New York and Genebra, 2008.

UNITED NATIONS CONFERENCE ON TRADE AND DEVELOPMENT. The 2008 food price crises: rethinking food security policies. G24 Discussion Paper Series, 2009.

WORLD TRADE ORGANIZATION. Agreement on agriculture. 1995. Disponível em: <http:/ /www.wto.org/ english/docs_e/legal_e/14-ag.pdf>. Acesso em: 19 jun. 2012.

WORLD TRADE ORGANIZATION. Agreement on subsidies and countervailing measures. 1995. Disponível em: <http://www.wto.org/english/docs_e/legal_e/24scm.pdf $>$. Acesso em: 18 jun. 2012. 
Para publicar na Revista de Direito Internacional, acesse o endereço eletrônico www.rdi.uniceub.br ou www.brazilianjournal.org.

Observe as normas de publicação, para facilitar e agilizar o trabalho de edição. 